\title{
Falling in the Elderly; A Clarification of Results
}

\author{
Mr. B.A. Mateen ${ }^{1}$ \\ $\mathrm{BSc}$ \\ $\&$ \\ Dr. F. J. Király ${ }^{2,3 *}$ \\ $\mathrm{PhD}$
}

${ }^{1}$ University College London, London, UK

${ }^{2}$ Department of Statistical Science, University College London, London, UK

${ }^{3}$ The Alan Turing Institute, London, UK

\section{Author for correspondence (*):}

Dr. Franz J. Király

Department of Statistical Science, University College London,

Gower Street London WC1E 6BT United Kingdom

Tel.: +44 - 20 - 76791259 Fax.: +44 - 20 - 31083105

E-mail: f.kiraly@ucl.ac.uk 


\section{Dear Editor,}

Upon reading the article "Falling in the elderly: Do statistical models matter for performance criteria of fall prediction? Results from two large population-based studies", which was recently published in the European Journal of Internal Medicine [1], we have arrived at several conclusions.

Firstly, we would like to commend the authors on their use of machine learning and out-of-sample validation. The former is used relatively rarely in prediction of clinically-relevant outcomes, and this study clearly demonstrates the potential usefulness of such mechanisms compared to simpler linear models. Moreover, the use of out-ofsample validation is equally infrequent, despite the clear need for such information to be able to adequately assess the validity of any predictive claims. As such, the methodological rigour of the research is quite clear.

However, we believe we have identified an error in the reporting of the data. Using the ANFIS example in Table 2C; the authors report the sensitivity as $91.9 \%$, and the specificity as 43.9\% [1]. Given the accepted definition of sensitivity as that of the 'true positive rate', which can be calculated using the following equation: TPR = $\mathrm{TP} /(\mathrm{TP}+\mathrm{FN})$ [2], the value should in fact be $43.8 \%$ for sensitivity. Using the equation for specificity (true negative rate): $\mathrm{TNR}=\mathrm{TN} /(\mathrm{TN}+\mathrm{FP})$ [2], the value for specificity should be $91.9 \%$. It appears as though the values for sensitivity, and specificity have been switched in Table 1 [1]. Furthermore, the equation for positive predictive value is: PPV $=\mathrm{TP}(\mathrm{TP}+\mathrm{FP})$. Thus, the PPV is actually $71.9 \%$, which has been mistakenly reported as the negative predictive value in the tables [1]. Although, this error does not seem to be present in table 3. The authors subsequent discussion based on these results therefore requires clarification. The incongruity of the results with previous studies in the literature [3], that they themselves have highlighted, appears to be an artifact of the aforementioned error. 


\section{$\underline{\text { References }}$}

[1] - Kabeshova A, Launay CP, Gromov VA, Fantino B, Levinoff EJ, Allali G, Beauchet O. Falling in the elderly: Do statistical models matter for performance criteria of fall prediction? Results from two large population-based studies. European journal of internal medicine. 2016 Jan 31;27:48-56.

[2] - D. Powers, "Evaluation: From precision, recall and f-measure to roc, informedness, markedness and correlation,"J. Mach. Learn. Technol., vol. 2, no. 1, pp. 37-63, 2011

[3] - Giansanti D, Macellari V, Maccioni G. New neural network classifier of fall-risk based on the Mahalanobis distance and kinematic parameters assessed by a wearable de- vice. Physiol Meas 2008;29:N11-9. 